\title{
A test of agent-based models as a tool for predicting patterns of pathogen transmission in complex landscapes
}

Kelly E Lane-deGraaf ${ }^{1,5^{*}}$, Ryan C Kennedy ${ }^{2,4}$, SM Niaz Arifin² ${ }^{2}$, Gregory R Madey², Agustin Fuentes ${ }^{3}$ and Hope Hollocher ${ }^{1}$

\begin{abstract}
Background: Landscape complexity can mitigate or facilitate host dispersal, influencing patterns of pathogen transmission. Spatial transmission of pathogens through landscapes, therefore, presents an important but not fully elucidated aspect of transmission dynamics. Using an agent-based model (LiNK) that incorporates GIS data, we examined the effects of landscape information on the spatial patterns of host movement and pathogen transmission in a system of long-tailed macaques and their gut parasites. We first examined the role of the landscape to identify any individual or additive effects on host movement. We then compared modeled dispersal distance to patterns of actual macaque gene flow to both confirm our model's predictions and to understand the role of individual land uses on dispersal. Finally, we compared the rate and the spread of two gastrointestinal parasites, Entamoeba histolytica and E. dispar, to understand how landscape complexity influences spatial patterns of pathogen transmission.
\end{abstract}

Results: LiNK captured emergent properties of the landscape, finding that interaction effects between landscape layers could mitigate the rate of infection in a non-additive way. We also found that the inclusion of landscape information facilitated an accurate prediction of macaque dispersal patterns across a complex landscape, as confirmed by Mantel tests comparing genetic and simulated dispersed distances. Finally, we demonstrated that landscape heterogeneity proved a significant barrier for a highly virulent pathogen, limiting the dispersal ability of hosts and thus its own transmission into distant populations.

Conclusions: Landscape complexity plays a significant role in determining the path of host dispersal and patterns of pathogen transmission. Incorporating landscape heterogeneity and host behavior into disease management decisions can be important in targeting response efforts, identifying cryptic transmission opportunities, and reducing or understanding potential for unintended ecological and evolutionary consequences. The inclusion of these data into models of pathogen transmission patterns improves our understanding of these dynamics, ultimately proving beneficial for sound public health policy.

Keywords: Agent-based model, Dispersal, Pathogen transmission, Landscape heterogeneity, GIS

\footnotetext{
* Correspondence: lanedegraaf.kelly@gmail.com

'Department of Biological Sciences, University of Notre Dame, Notre Dame,

IN, USA

${ }^{5}$ Current address: Odum School of Ecology, University of Georgia, Athens,

GA, USA

Full list of author information is available at the end of the article
}

\section{Biomed Central}

(c) 2013 Lane-deGraaf et al.; licensee BioMed Central Ltd. This is an Open Access article distributed under the terms of the Creative Commons Attribution License (http://creativecommons.org/licenses/by/2.0), which permits unrestricted use, distribution, and reproduction in any medium, provided the original work is properly cited. 


\section{Background}

An ongoing need exists for an enhanced toolkit for predicting spatial patterns of pathogen transmission [1-4]. While current models incorporate spatial aspects of the host [5,6], pathogen [7-9], or more rarely, both $[10,11]$, many current models of infectious disease ignore the more complex landscape features, including interactions between hosts, which can be mitigated or facilitated by landscape complexity [12,13]. Pathogen transmission potential is an integrated measure of both infectivity and an individual's opportunity for encountering the pathogen in the environment or through contact with other infectious individuals [14]. Therefore, models of pathogen infection must examine this transmission potential and focus on how landscape features directly influence this potential and the resulting patterns of pathogen spread. The continued shift in research emphasis towards efforts concentrating on the underlying ecological determinants and spatial dynamics of pathogen transmission will result in more effective global public health policy [15-17].

Employing geographic information systems (GIS) data as a tool in epidemiologic analyses is not new, given the ability of GIS to incorporate spatial and non-spatial data in one system [18]. Colwell and colleagues (1996) successfully implemented research programs using GIS data of Bangladesh to more completely understand the transmission of Vibrio cholerae by modeling it as a component of the environment. Outbreaks were shown to be both seasonal and geographically localized, influenced strongly by the presence of estuaries and major rivers [19]. Modeling of pathogen transmission and spread of infectious diseases with a focus on GIS analysis has been undertaken in several outbreaks and epidemics, including plague (Yersinia pestis) in the Southwestern United States, rabies in Trinidad, and Chagas disease vectors in Colombian villages [20-22]. These studies demonstrate that analysis of pathogen transmission patterns is enhanced through the flexibility in analyzing spatial data inherent to the GIS system.

Recently, agent-based models (ABMs), or individualbased models, have been effectively employed as an enhanced tool to address the spatial dynamics of pathogen transmission $[7,23,24]$. These models explicitly represent individual entities in the system under study and can realistically accommodate extreme heterogeneity among the agents by allowing individuals to incorporate spatial interactions into the simulations directly [25]. This flexibility permits ABMs to account for population outliers and long-tailed distributions and to model rare, albeit important, events in the system under study [7]. Agentbased modeling is therefore ideal for addressing complex questions regarding how hosts and pathogens navigate a complex landscape. Recently developed ABMs have been used to elucidate infectious disease dynamics in systems as disparate as demonstrating the process of granuloma formation following a tuberculosis infection [26], evaluating influenza vaccination strategies in Italy, with a focus on implementation campaigns mitigating a global pandemic to $\mathrm{H} 5 \mathrm{~N} 1$ [8], and understanding the relationship between vector ecology, human behavior, and spread of African sleeping sickness [10].

\section{Host behavior and ecology}

Macaque species are found throughout Asia and in parts of Africa, with the fascicularis subgroup having an extensive range throughout much of Southeast Asia. Longtailed macaques (Macaca fascicularis) thrive in a variety of habitat types, including forests, grasslands, semideserts, and most especially, urban landscapes [27], often living commensally with humans. While macaques are generally considered to be frugivorous, long-tailed macaques are known to have a highly flexible diet and can be considered, in parts of their range, to be omnivorous. Male dispersal is common, while females remain in their natal group. Little is known about dispersal duration or distance [27]; however, long-distance dispersals have been documented [28]. Gene flow between population groups is maintained by male dispersal as well as by group fission events, especially common as population size increases. Thus, long-tailed macaques thrive in complex, anthropogenic landscapes and can disperse across wildly variable habitats.

On the island of Bali, Indonesia, a system of temple complexes act as core use areas for long-tailed macaques (Macaca fascicularis) [29-32]. While the macaques' home ranges extend well beyond the confines of the temple complexes, a substantial segment of a given population can be found in and around these temples on a regular basis. Dispersing male macaques may act as both units of gene flow between seemingly isolated macaque populations and as mechanisms of pathogen transmission across the island [29]. Human land use patterns have resulted in a mosaic of riparian forest, small forest patches, agricultural lands, and urban areas across much of the island. The broad distribution of macaque populations on Bali suggests that macaques use this human-modified landscape by exploiting agriculturallydominated, riverine links between populations for dispersal and the sanctuary nature of temples as stabilized food resources [29]. This protection and resource availability has allowed macaques to exist in moderately high densities alongside high human densities [31].

\section{Pathogen ecology and epidemiology}

Gastrointestinal parasites are among the most prevalent suite of parasites and pathogens globally, with representatives found in nearly all mammal species and causing 
morbidity in nearly all individuals at some point in their lifetime [33]. The success of this suite of parasites is due, in large part, to their mode of transmission. Relying on the fecal-oral route and often occurring with environmentally stable infective stages, infectious agents pass through the gut of an infected individual, are deposited in water or on plant matter, and are ultimately consumed, completing the transmission cycle [34]. The environmentally stable infective stage makes the spatial transmission of gastrointestinal parasites of special relevance. Landscape type and quality have been shown to be important in the prevalence and intensity of intestinal parasites [35-37]. For example, intestinal parasite burden was significantly greater in low quality, fragmented habitat in populations of two species of howler monkeys (Alouatta palliata and A. pigra) [38].

It is estimated that more than 500 million people are infected with at least one species of Entamoeba at any given moment [34]. Infection rates increase with impoverished economies and lack of access to clean drinking water. Both Entamoeba histolytica and E. dispar, along with at least two other amoebas (Iodamoeba and Endolimax) infect humans, domestic animals, and wildlife species, including non-human primates $[34,35,38,39]$. While E. histolytica is linked to numerous cases of diarrhea and more than 100,000 human deaths/year, $E$. dispar is largely un-symptomatic, causing neither disease nor tissue degeneration [40]. Both species of Entamoeba have been found in macaques throughout their range, including on the island of Bali, Indonesia $[35,41,42]$. The similarity in transmission strategy and phylogeny coupled with highly disparate disease severities makes $E$. histolytica and $E$. dispar an ideal model system for examining the effect of landscape variability on host dispersal and pathogen transmission.

\section{Modeling host movement and pathogen transmission}

LiNK, the ABM presented here, incorporates landscape features critical to understanding pathogen transmission patterns by using GIS layers of the actual system's landscape $[29,43]$. The powerful spatial analysis permitted through the use of GIS data combined with the strength and utility of $\mathrm{ABM}$ provides a mechanism to understand the spatial context critical for understanding patterns of pathogen transmission. LiNK has the ability to generate predictions regarding host dispersal and pathogen distributions based on the anthropogenic landscape, humanwildlife interactions, host behaviors and interactions, and pathogen life histories at island-, population-, and individual levels.

Here, we present an agent-based model of host (macaques) and pathogen (gastrointestinal parasites) movement through the Bali landscape. First, we aim to determine the impact of the inclusion of landscape information on patterns of macaque dispersal. We hypothesize that the inclusion of landscape information into our model will alter the dispersal pattern of macaques from isolation by distance, as predicted in the absence of landscape information, to one of dispersal linked by habitat type. We then compare the difference between modeled dispersal patterns generated with the inclusion of landscape information to that of actual macaque gene flow patterns, as measured by genetic distance. We hypothesize that the inclusion of landscape information into our model of macaque dispersal will correlate better to measured genetic distance than when landscape information is excluded. Finally, we explore the likely path and rate of pathogen transmission of two gastrointestinal parasites - Entamoeba histolytica and E. dispar - modeled using varying pathogen virulence, infectivity, and infectiousness parameters. We hypothesize that the inclusion of landscape information will result in environmental context dependence in rate and route of infection, with landscape heterogeneity mitigating overall infection. We also hypothesize differences between the two parasites independent of landscape features with the less virulent parasite $-E$. dispar reaching overall greater distances from the site of initial infection due the host's ability to maintain dispersal patterns as though healthy.

\section{Methods}

\section{Model description}

LiNK is an agent-based model created and implemented using GIS maps of Bali [42]. GIS layers include data on coastline, rivers and lakes, forest, rice agriculture, urban areas, roadways, and temple locations (see Figure 1), created via remote sensing and GPS ground-checking. Within LiNK, macaques, or agents, 'live' in the landscape making reproductive and dispersal decisions based on behavioral data known at the model's development $[27,30,31]$. Decisions to disperse are based on male macaque age, with dispersal occurring between the ages of six and eight. Once a macaque has left his natal population, all decisions regarding direction and feasibility of travel are based on both prior location and the landscape parameters provided by the GIS layers. Agents travel in a direction that maximizes their time spent in preferred landscape types while avoiding the last occupied location.

Transmission dynamics are modeled based on macaque dispersal and a set of variable parameters specific to the pathogen of interest: virulence, infectivity, infectiousness, latency period, clearance time, and immunity development. Latency period, clearance time, and immunity development are timing parameters, described in Figure 2. Virulence is modeled as the pathology of the parasite, or the level of agent or macaque illness required to optimize transmission of the parasite. This 


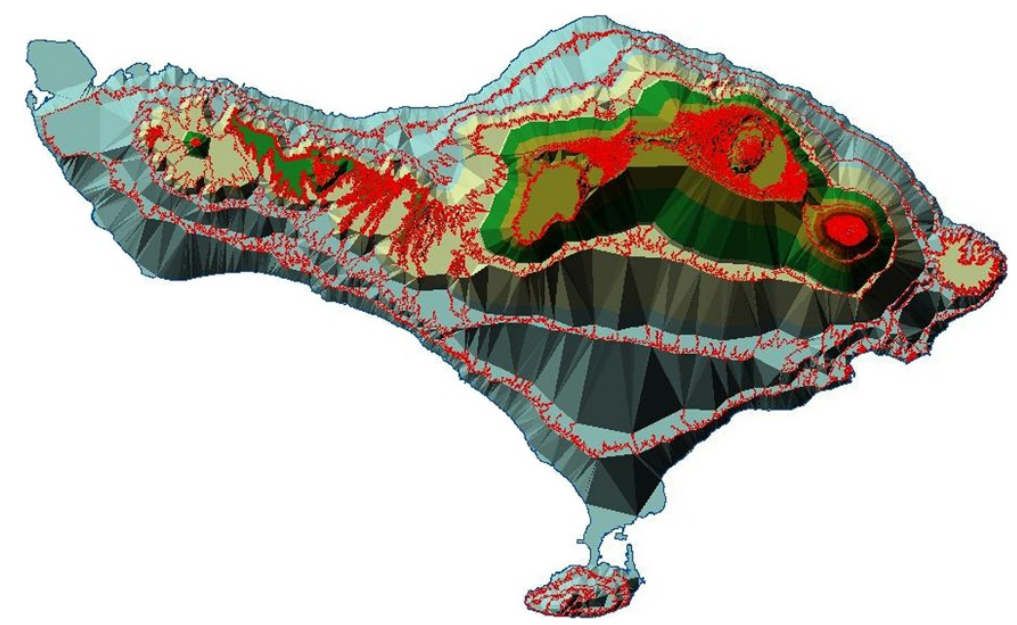

Figure 1 Map of Bali, based on GIS data (Southern et al. [32]), with forest-covered areas shown in green/green-drab and elevation gradients shown in relief. Red lines indicate areas of sharp changes in slope.

parameter impacts both movement ability and survivorship. Infectivity is modeled as the area around an infected agent in which another agent is at risk of becoming infected. While a measure of distance, infectivity remains independent of a unity of distance due to the conversion necessary for applying the distance across latitude and longitude. Infectiousness is modeled as the likelihood of infecting a susceptible agent.

\section{Model development details}

LiNK is a spatially explicit model that consists of agents representing macaques and GIS layers representing the landscape including the coastline of Bali, cities, forests, rivers and lakes, rice fields, roads, macaque temple sites, and 100 ha buffer zones around macaque temples. At each time step, agents evaluate potential new positions, noting their current landscape and directional bias. Dispersing macaques enter temples, depending on their proximity to individual temples in the landscape. Female macaques have a $25 \%$ chance to give birth annually from 3-13 years of age. Macaque movement through the landscape was implemented based on previous findings $[29,31]$, including dispersal distances and habitat preferences. Male dispersal and female philopatry were

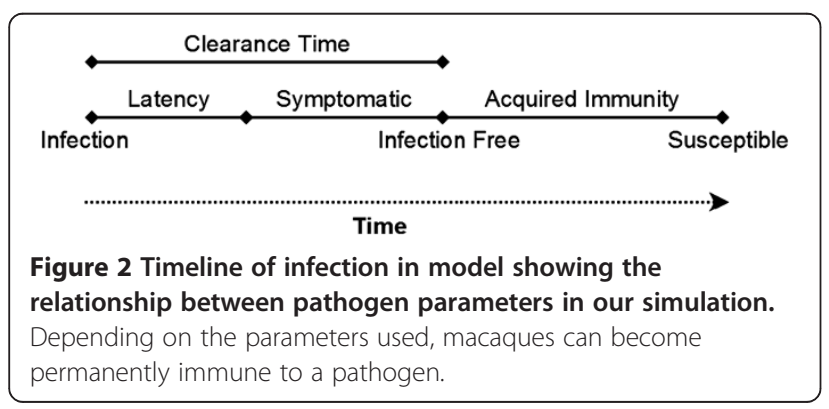

confirmed through sequencing of mitochondrial and $Y$ DNA loci [29]. This movement through weighted probabilities facilitates the overall purpose of the model - to understand how landscape dynamics influence host movement.

Patterns of infection spread throughout Bali emerge over time, in accordance to host movement through the landscape. Macaques are aware of their current and surrounding landscape, which they use to make movement decisions. Macaques interact with other macaques both while dispersing and within temples. Upon infection, the pathogen is in a latent period, which refers to the length of time before the infection becomes symptomatic. After completing the symptomatic phase, a macaque will become infection free and clear the pathogen, which prevents further transmission of the pathogen. Immunity development occurs after the infection has been cleared from individual macaques, ending when the again becomes susceptible. However, if this parameter is set to zero at initialization, re-infection can occur immediately after clearance. Transmission of the pathogen between macaques depends largely on infectiousness and infectivity. Infectivity is described as the transmission ring which both macaques have to be within to transfer infection; infectiousness is the likelihood that an infection will occur. Virulence is a measure of the severity of the infection. Higher virulence infections lower the chance of movement of the infected macaque.

The model was coded in Java [44] with the Repast simulation toolkit [45]. Repast and OpenMap [46] were utilized to display the model, while GeoTools [47] and JTS Topology Suite [48] were used to interact with the spatial information. The choice of tools used in this study was primarily driven by the necessity to process and visualize GIS data and to be cross-platform and 
open-source, where possible. For a more technical discussion of the algorithms used in defining these measures and for a more detailed description on model building, see the Overview, Design Concepts, and Details (ODD) available as an Additional file 1, which follows the protocol for describing agent-based models as suggested by Grimm et al. [43,49].

\section{Simulation experiments \\ Model verification \& validation}

Two main categories of model verification and validation were performed - internal sensitivity analyses and external confirmation of model predictions. Internal sensitivity analyses were further partitioned into two components - system functionality and biological relevance. System functionality analyses have been previously described [50] and will not be discussed here. Biological relevance analyses determined the effects of incorporating landscape data into the transmission model. All scenarios were repeated at four specific initial infection sites: two temples with population sizes greater than 300 individuals (Padangtegal or PU and Alas Kedaton or AK) and two temples with population sizes less than 60 individuals (Alas Nengahn or AN and Mekori or MK). These sites can also be partitioned by relative landscape heterogeneity, with two sites in largely homogeneous landscapes (Alas Kedaton or AK and Alas Nengahn or $\mathrm{AN}$ ) and two sites in predominantly heterogeneous landscapes (Padangtegal or PU and Mekori or MK). We report the overall number of infections, the number of infections occurring in males and females, and the number of deaths occurring due to age, dispersal risk, and infection.

Two major sets of biological relevance analyses were performed: baseline landscape inclusion tests and pathogen parameterization tests. In the baseline landscape inclusion tests, we ran 50 replicates at each site of initial infection and compared the above three metrics occurring first with all GIS layers included and then with only the coastline available (no landscape data included). Using $\mathrm{R}$, t-tests were performed to compare results by population size and by landscape heterogeneity. An ANOVA was used to compare individual death types as a function of inclusion of landscape data. The effects of individual landscape layers (forest, rice agriculture, urban areas, and buffer zones) were also compared across population size and landscape heterogeneity in order to assess the impact of specific landscape layers on macaque dispersal and pathogen transmission in our model. In the pathogen parameterization tests, we compared the above three metrics across high (85 out of $100)$, moderate (50 out of 100$)$, and low (15 out of 100) levels of virulence, infectivity, and infectiousness, with 200 replicates of the model run for each scenario. The results of both the baseline landscape inclusion and pathogen parameterization verification and validation analyses are presented in an Additional file 2.

\section{External verification \& validation Landscape effects}

To determine the overall role of the landscape on macaque movement, we compared the results of a series of simulations with all landscape information available, only landscape information about the coastline available (required for all simulations), and with individual landscape components removed, e.g. with the GIS layer representing forest cover removed. In this analysis, the total number of infections were recorded, with the results from 200 replicates/initial starting population averaged and compared with t-tests, for the analysis of all landscape information (ALL) versus no landscape information included (COAST ONLY), and ANOVA, for the analysis of effects of removing individual landscape information layers. Differences in infection pattern were also compared using a Mantel test, with an isolation-by -distance model hypothesized if the inclusion of landscape data plays no role in macaque movement $[51,52]$.

\section{Macaque dispersal}

Given that macaque dispersal distance is expected to correlate with genetic distance [53-55], our next analysis compared genetic distance to modeled dispersal distance to externally confirm our predictions of landscape influenced macaque dispersal patterns. To do this, we parameterized the model to record dispersal events initiated at five populations located across the island. Dispersal events were recorded as the number of successful entries into each new population from the origination site, averaged over 300 replicates. We repeated the analysis including and excluding landscape information. Using R, we performed a Mantel test to determine statistical similarity between our modeled dispersal distance and measured genetic distance from genetic analysis of 15 macaque populations throughout Bali, using microsatellite analysis across 13 loci [29], Lane-deGraaf et al., unpublished data. All collections were approved by the University of Notre Dame IACUC (protocol 07-001 and 09-011) and the Indonesian Institute of Science (permit number 662.02/1090.DIII).

\section{Pathogen transmission}

Two gastrointestinal parasites were used to examine the direct impact of the inclusion of landscape information on parasite transmission. In this analysis, pathogen parameter values were set to represent $E$. histolytica and E. dispar [56], with the major differences focused on virulence, infectivity, and infectiousness (See Table 1). Two hundred replicates of each infection scenario were 
Table 1 Values used to parameterize model for the analysis of E. histolytica and E. dispar spread across Bali

\begin{tabular}{cccc}
\hline Parameter & Value & E. histolytica & E. dispar \\
\hline Virulence & (0-100 range $)$ & 75 & 20 \\
Infectivity & (0-100 range $)$ & 60 & 35 \\
Infectiousness & (0-100 range $)$ & 60 & 40 \\
Latency Period & Variable, in timesteps & 7 timesteps & 7 timesteps \\
Clearance time & Variable, in timesteps & 28 timesteps & 28 timesteps \\
Immunity Time & Variable, in timesteps & 120 timesteps & 120 timesteps \\
Natural resistance & $(0-100$ range $)$ & 1 & 1 \\
\hline
\end{tabular}

performed. For each parasite, we used t-tests to compare the number of overall infections occurring while varying the initial infection sites across landscape heterogeneity and population size (see above population descriptions). We also measure the number of infections occurring in each major landscape type (forest, rice agriculture, and urban areas), using t-tests to compare E. histolytica and E. dispar spread. Finally, we use ANOVA to compare the distance traveled from initial infection site, determining spread rate by averaging the number of infections reaching each temple.

\section{Results}

\section{Landscape effects}

Significant differences were found in the number of temple sites reached by infection between analyses that included and excluded landscape information $(t=-3.037$, $\mathrm{p}<0.01$ ), with a greater number of temples reached in the absence of landscape data (Figure 3). This suggests that macaques using landscape information are limited in their movement by landscape barriers. When exami- ning the effects of individual landscape layers, we found that the exclusion of data on rivers led to a significant reduction in temples reached via dispersal $(\mathrm{F}=2.769$, $\mathrm{p}<0.012$ ), while the exclusion of urban landscape information (which includes the combined effects of roads and cities) resulted in a significant increase in dispersal distances $(\mathrm{F}=2.332, \mathrm{p}<0.014)$, reaching a greater number of temples and at a greater distance from their site of origin. This suggests that inclusion of additional landscape information identifies an emergent property of the landscape itself, with the combined urban landscape responsible for an increase in dispersal distances greater than would be predicted based on the roads or cities layers independently (Figure 3). Finally, the inclusion of all available landscape information resulted in a significant reduction in overall dispersal distances and number of temples reached $(\mathrm{F}=2.462, \mathrm{p}<0.02)$.

\section{Macaque dispersal}

Significant correlations were found between genetic distance and modeled dispersal distance from each of the five sites of origination when landscape information was included in the analysis, located in the north (correlation value $=0.33, \mathrm{p}=0.034$ ), south (correlation value $=0.49$, $\mathrm{p}=0.008$ ), east (correlation value $=0.40, \mathrm{p}=0.014$ ), west (correlation value $=0.34, \mathrm{p}=0.028$ ), and center (correlation value $=0.52, \mathrm{p}=0.002$ ) of the island. However, in the absence of landscape information, no correlations were observed between genetic distance and modeled dispersal distance at any of the five sites of origination $(\mathrm{N}$ : correlation value $=0.01, \mathrm{p}=0.394 ; \mathrm{S}$ : correlation value $=0.01, \quad \mathrm{p}=0.411 ; \mathrm{E}:$ correlation value $=0.01$, $\mathrm{p}=0.342$; W: correlation value $=0.003, \mathrm{p}=0.522$; $\mathrm{C}$ : correlation value $=0.01, \mathrm{p}=0.466)$. The tightest relationship

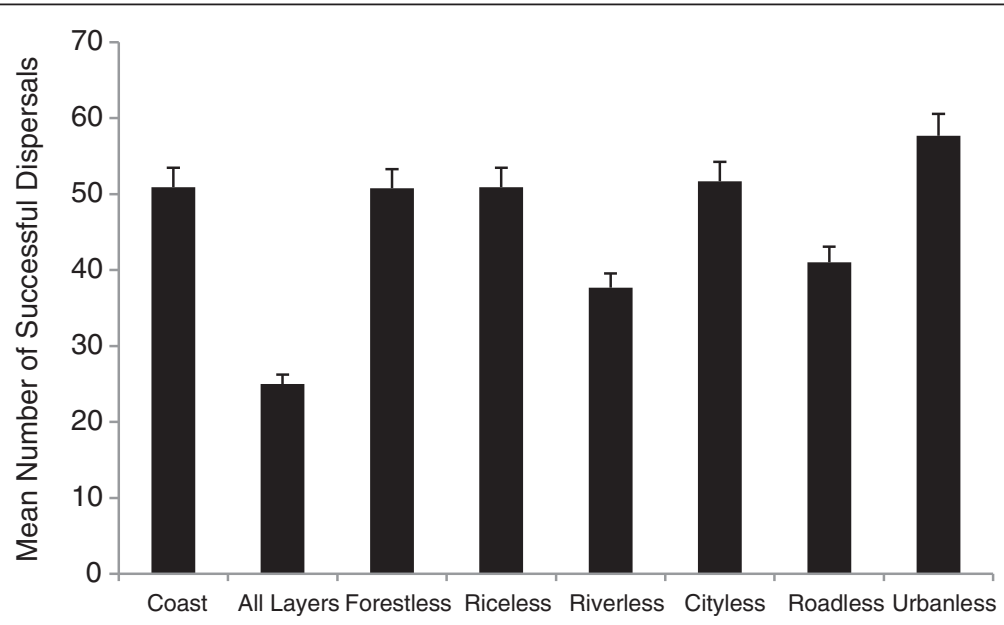

Figure 3 Average number of infections/temple site with the exclusion of specific landscape layers. Exclusion analysis began with only the coastline GIS layer, with all layers included, and finally with each layer cycled off independently. Note the substantial disparity between replicates with only the coast available and with all layers available as well as the increase in infection when the urban layers (road and city combined) were left off. 
between measured genetic distance and modeled dispersal distances occurred at the center, most anthropogenically-complex landscape on the island - Padangtegal (PU) - suggesting that macaques in LiNK are making landscape-driven decisions in much the same way as the long-tailed macaques of Bali.

\section{Pathogen transmission}

The number of overall infections was greatest when infection originated in either Padangtegal (PU) or Alas Kedaton (AK) - the two largest macaque populations. Landscape heterogeneity had no overall impact at this level of analysis. At all initial infection sites, E. dispar infections significantly outnumbered $E$. histolytica infections (PU: $\mathrm{t}=27.09, \mathrm{p}<2.2 \mathrm{e}^{-16} ; \mathrm{AN}: \mathrm{t}=2.5733, \mathrm{p}=0.01$; AK: $\mathrm{t}=22.51, \mathrm{p}<2.2 \mathrm{e}^{-16} ; \quad \mathrm{MK}: \mathrm{t}=2.78, \mathrm{p}=0.006$; Figure 4). When infection was examined by GIS layer, we found that infections were the most numerous in the forest dominated landscape. Rice agriculture lands and urban areas had infection occurring at lower levels (Figure 5). E. histolytica infections occurred at a significantly higher rate than E. dispar infections, in all landscape types and at each initial site of infection except Mekori (MK) where there was no difference in infection rate (Figure 5, Table 2).

At all sites, E. dispar reached greater distances at a significantly higher rate than E. histolytica (Figure 6, Table 3), supporting our hypothesis of more virulent pathogens limiting dispersal. However, distances with the highest rate of infection were not $0-10 \mathrm{~km}$ from the initial infection site, as predicted. At Mekori (MK), significantly greater numbers of infections reached temples

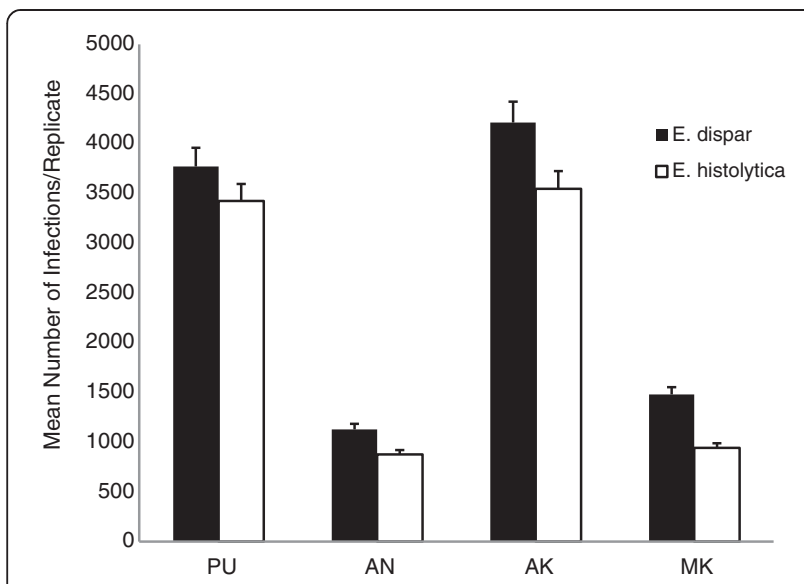

Figure 4 Differences in modeled infection rates of $E$. histolytica and $E$. dispar, originating from four sites in Bali, Indonesia. Each analysis is the comparison of the number of infections occurring when modeling $E$. histolytica or $E$. dispar, by initial site of infection (PU: $t=27.0996, p<2.2 e^{-16} ; A N: t=2.5733, p=0.01164 ; A K: t=22.505$, $\left.p<2.2 e^{-16} ; M K: t=2.7825, p=0.006519\right)$. Standard error bars shown; d.f. $=199$ for each site of analysis. at distances of $20-30 \mathrm{~km}$ and 40-50 km than any other distance, including $0-10 \mathrm{~km}$ from the initial site of infection. At Alas Kedaton (AK) and Alas Nengahn (AN), increases in the number of infections occurred in more distant temples. AK had infection peaks at temples 30-40 km and temples greater than $50 \mathrm{~km}$ from the initial infection site, and AN had infection peaks at temples greater than $40 \mathrm{~km}$ from the initial site of infection. These increases in infections at distances not immediately surrounding the site of initial infection suggests that landscape heterogeneity plays an important role in shaping the movement of macaques and pathogens through the landscape.

\section{Discussion}

The incorporation of host movement and dynamic pathogen parameters combined with the inclusion of GIS data into our ABM allowed us to generate predictions of how macaque dispersal would be influenced by the landscape. In comparing these predictions against genetic evidence, our model was fully supported in predicting patterns of gene flow across the landscape. Our results show that an ABM which incorporates landscape information generates patterns of dispersal that accurately reflect actual dispersal patterns, as measured by genetic distance between populations. Most importantly for this system, and other anthropogenicallycomplex landscapes and urban wildlife systems, the inclusion of urban landscape information facilitated two unexpected results. First, macaque movement was most accurately predicted in the central core of the island where the landscape is highly heterogeneous and mostly characterized by human landscape features. Second, urban landscapes mitigated pathogen transmission by reducing the infection rate of both pathogens in the more heterogeneous, urban landscape. This accuracy in modeling macaque dispersal provided the foundation for then comparing how the transmission of two closely related pathogens, but with two distinctly different severities, would be impacted by the landscape more broadly. We found that the inclusion of landscape data increased the distance from the initial site at which infection peaked in both parasites, but that in all cases, E. dispar successfully reached populations at further distances at higher rates. Due primarily to macaques favoring forest patches, infections outside of temple complexes occurred at the greatest rate in this landscape layer. Interestingly, E. histolytica had a significantly higher rate of transmission between macaques outside of temples. Thus, specific landscape features (forest patches and rice agriculture) allowed infection to thrive more than others (urban areas and buffer zones), favoring the more virulent pathogen even when the less virulent pathogen was able to more successfully reach other temple 


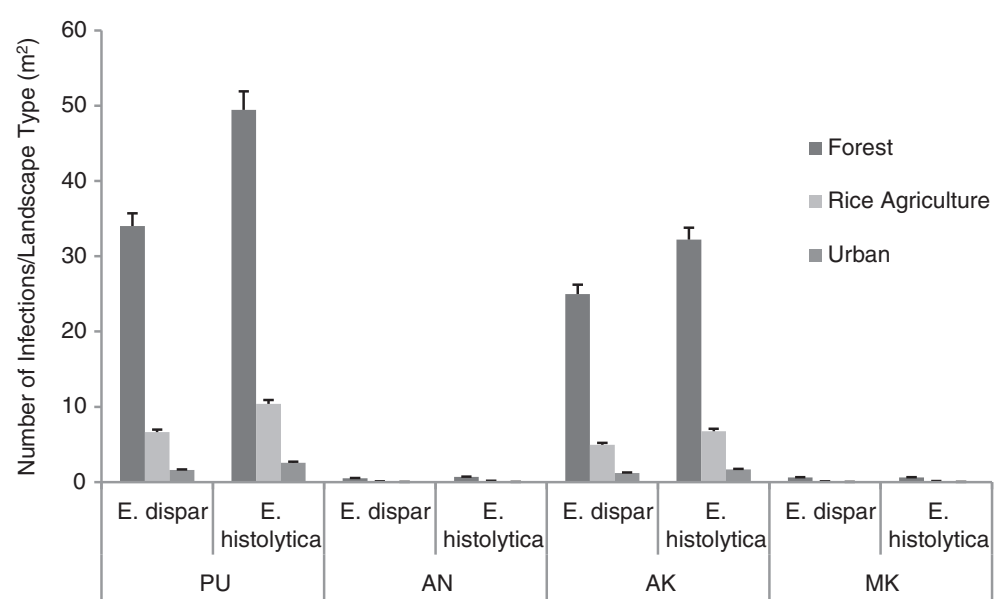

Figure 5 The mean number of infections occurring island-wide, originating at one of 4 sites, reported as the number of infections occurring in each dominant landscape type. Values are reported as the number of infections per $\mathrm{m}^{2}$ of habitat type surrounding the infection site. Significant differences occur between E. histolytica and E. dispar in all landscape types when infection originated at PU (See Table 2 for $t$ and $p$ values). Significant differences in rate of infection between parasites also occurred when infection originated at AK, but only in urban areas. Standard error bars shown.

populations. This dynamic favors the spread of the less virulent pathogen to macaque populations, making it the more probable source of infections resulting from human-macaque interactions at temple sites, while the occasional, yet significant, human-macaque interactions occurring outside of temple sites is more likely to favor the transmission of the more virulent pathogen.

Table 2 T-tests and $p$ values associated with Figure 5, comparing rate of infection occurring in dominant landscape types when infection originated at each of 4 sites of initial infection

\begin{tabular}{lcc}
\hline Comparison & t value & p value \\
\hline PU: & $\mathbf{2 . 2 8 2 4}$ & $\mathbf{0 . 0 3 5 6 2}$ \\
$\quad$ Forest & $\mathbf{2 . 9 7 3 7}$ & $\mathbf{0 . 0 0 6 4 3 1}$ \\
Rice Agriculture & $\mathbf{6 . 3 5 1 7}$ & $\mathbf{4 . 0 3 8 \mathrm { e } ^ { - \mathbf { 8 } }}$ \\
$\quad$ Urban Area & & \\
AN: & 1.4487 & 0.1508 \\
$\quad$ Forest & 1.8208 & 0.07183 \\
Rice Agriculture & 1.3017 & 0.1962 \\
Urban Area & & \\
AK: & 1.0147 & 0.3320 \\
$\quad$ Forest & 1.7067 & 0.1085 \\
Rice Agriculture & $\mathbf{6 . 0 4 9 2}$ & $\mathbf{3 . 6 8 2 \mathrm { e } ^ { - \mathbf { 7 } }}$ \\
$\quad$ Urban Area & & 0.1144 \\
MK: & 1.5944 & 0.2170 \\
$\quad$ Forest & 1.2429 & 0.2337 \\
Rice Agriculture & 1.1987 & \\
Urban Area &
\end{tabular}

For each analysis, $\mathrm{df}=199$. Significant differences are bolded.
While LiNK focuses on the spatial patterns of host movement and gastrointestinal pathogen transmission patterns in an island population of long-tailed macaques, the results presented here demonstrate the importance of incorporating environmental components and landscape features more generally into models of pathogen transmission. Landscape heterogeneity is significant in shaping the pattern of both macaque dispersal and gut pathogen transmission across the island. We have shown that distance alone is not necessarily a significant indicator of transmission success, as demonstrated by the peaks in infection at further distances from individual populations. Rather, it is the combination of distance from initial infection site and landscape complexity that serve as the best predictor of infection patterns. We also demonstrate that some level of landscape heterogeneity serves to slow the spatial dimension of infection, which has important implications for land use management. Within the context of bidirectional pathogen transmission between humans and non-human primates, the significance of landscape dynamics on pathogen transmission potential could be even more significant when considering the rare, but important, occurrence of novel infectious disease emergence. Increasing human-wildlife interactions make it important to consider the impact of landscape complexity on pathogen transmission patterns, which can facilitate infectious disease emergences.

Establishing how patterns of infection vary spatially represents a key first step in understanding the ecological and epidemiological links between anthropogenic land use and disease [15]. ABMs are one tool for understanding how varying land uses can impact the spatial pattern of infection. Given this, the potential for ABMs 


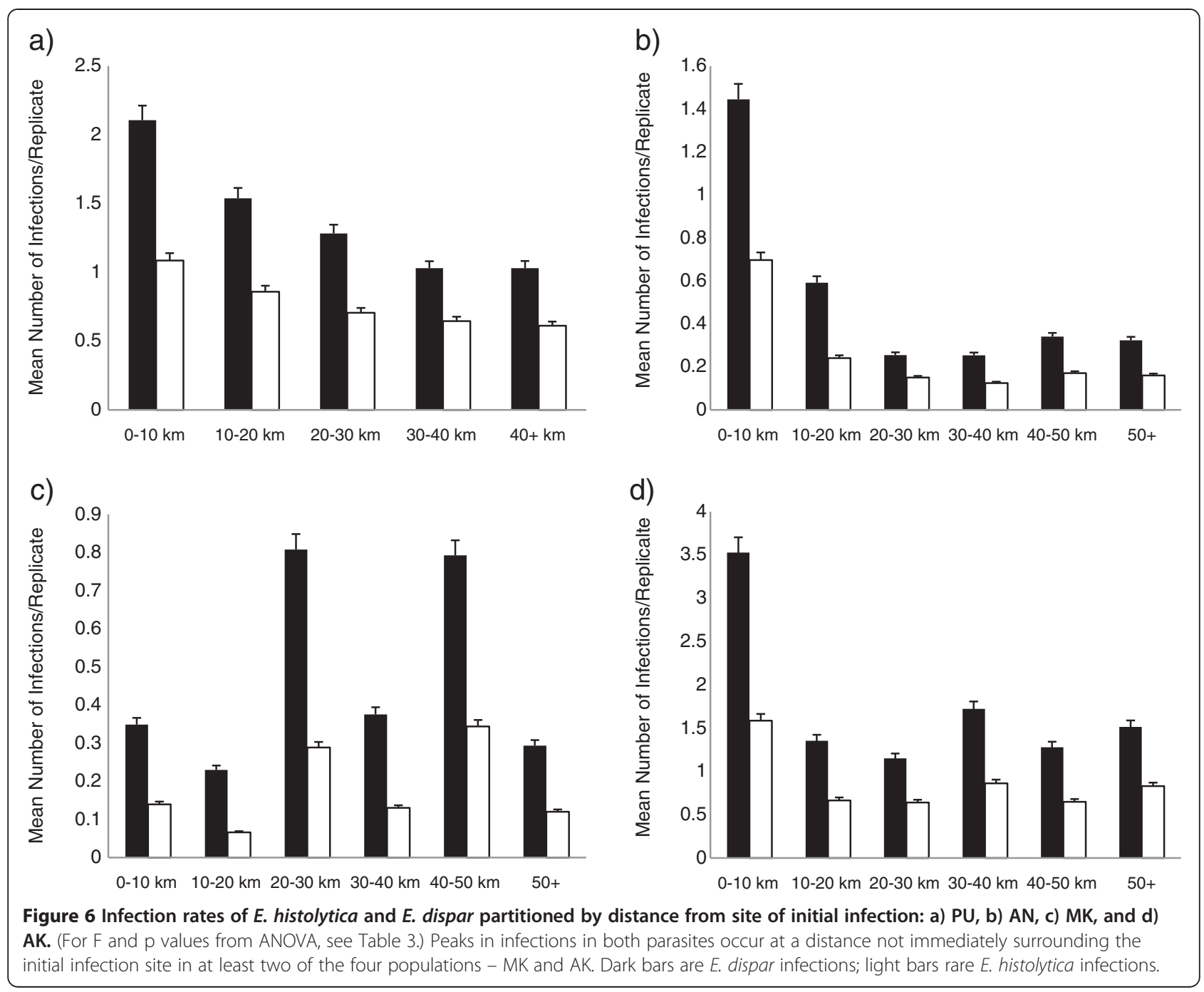

to be used as a tool in the development of a disease management strategy, either a chronic invasive pathogen such as bovine tuberculosis in South Africa [57] or in response to a more acute outbreak such as influenza [58], is significant. Disease management strategies include large-scale vaccination efforts, administration of therapeutics, or often culling of infected individuals $[59,60]$. However, these efforts can be challenging. Vaccination efforts and administration of therapeutics often end when funding issues arise [61]. Culling has been shown to be often inefficient and ineffective [62-65]. Moreover, these efforts often have unintended ecological and evolutionary consequences [62-65]. However, the incorporation of complex landscape information and host behaviors into the planning of disease management strategies can provide a more realistic representation of the spatial pattern of infection.

Understanding the role of complexity is one of the most significant aspects in the effective analysis of infectious disease dynamics [66]. Recently, we have demonstrated that the landscape, including anthropogenic elements of the landscape, has an important factor in explaining infection intensity of specific parasites [35]. By identifying the emergent properties of populations and landscapes based on the decisions of individual hosts, LiNK provides a basis for understanding how the complexities of the anthropogenic landscape influence patterns of pathogen transmission at the scale of individuals, populations, and metapopulations. LiNK's success at modeling actual dispersal distances in a complex landscape demonstrates the utility of ABMs in predicting patterns of host dispersal and pathogen transmission. Further, while the focus of this analysis was on the spatial patterns of transmission of gastrointestinal pathogens, which have direct life cycles, ABMs incorporating complex landscapes have also been utilized for both directly and indirectly infecting pathogens, successfully incorporating intermediate hosts as well $[10,67]$. For example, the spatial spread of Human African Trypanosomiasis was successfully modeled using an ABM, which 
Table 3 ANOVA results comparing $E$. dispar and $E$. histolytica spread from four sites of initial infection (Figure 6)

\begin{tabular}{|c|c|c|c|}
\hline Comparison: & F value & $\mathrm{p}$ value & Tukey HSD \& Distance Category \\
\hline \multirow[t]{4}{*}{ E. dispar from $\mathrm{PU}$} & 85.533 & $<2.2 \mathrm{e}^{-16}$ & 0-10 km* from 10-20 km, 30-40 km; \\
\hline & & & $10-20 \mathrm{~km} *$ from $20-30 \mathrm{~km}, 40-50 \mathrm{~km}$; \\
\hline & & & $20-30 \mathrm{~km}^{*}$ from $30-40 \mathrm{~km}$; \\
\hline & & & $30-40 \mathrm{~km}^{*}$ from $40-50 \mathrm{~km}$ \\
\hline \multirow[t]{4}{*}{ E. histolytica from PU } & 49.84 & $<2.2 \mathrm{e}^{-16}$ & 0-10 km* from $10-20 \mathrm{~km}, 30-40 \mathrm{~km}$; \\
\hline & & & $10-20 \mathrm{~km} *$ from $20-30 \mathrm{~km}, 30-40 \mathrm{~km}, 40-50 \mathrm{~km}$; \\
\hline & & & $20-30 \mathrm{~km}^{*}$ from $30-40 \mathrm{~km}, 40-50 \mathrm{~km}$; \\
\hline & & & $30-40 \mathrm{~km}^{*}$ from $40-50 \mathrm{~km}$ \\
\hline \multirow[t]{2}{*}{ E. dispar from AN } & 27.74 & $<2.2 \mathrm{e}^{-16}$ & 0-10 km* from all other distances; \\
\hline & & & $10-20 \mathrm{~km} *$ from all other distances \\
\hline \multirow[t]{2}{*}{ E. histolytica from AN } & 16.311 & $5.773 e^{-16}$ & 0-10 km* from all other distances; \\
\hline & & & $10-20 \mathrm{~km} *$ from $20-30 \mathrm{~km}, 30-40 \mathrm{~km}$ \\
\hline \multirow[t]{4}{*}{ E. dispar from $A K$} & 57.551 & $<2.2 \mathrm{e}^{-16}$ & 0-10 km* from all other distances; \\
\hline & & & $10-20 \mathrm{~km}^{*}$ from $30-40 \mathrm{~km}$; \\
\hline & & & $20-30 \mathrm{~km}^{*}$ from $30-40 \mathrm{~km}, 50+$; \\
\hline & & & $30-40 \mathrm{~km}^{*}$ from $40-50 \mathrm{~km}$ \\
\hline \multirow[t]{4}{*}{ E. histolytica from AK } & 30.841 & $<2.2 \mathrm{e}^{-16}$ & 0-10 km*from all other distances; \\
\hline & & & $10-20 \mathrm{~km}^{*}$ from $30-40 \mathrm{~km}$; \\
\hline & & & 20-30 km* from 30-40 km, 50+ km; \\
\hline & & & $30-40 \mathrm{~km}^{*}$ from $40-50 \mathrm{~km}$ \\
\hline \multirow[t]{5}{*}{ E. dispar from $\mathrm{MK}$} & 26.886 & $<2.2 \mathrm{e}^{-16}$ & 0-10 km* from 20-30 km, 40-50 km; \\
\hline & & & $10-20 \mathrm{~km} *$ from $20-30 \mathrm{~km}, 40-50 \mathrm{~km}$; \\
\hline & & & 20-30 km* from 30-40 km, 50+ km; \\
\hline & & & $30-40 \mathrm{~km}^{*}$ from $40-50 \mathrm{~km}$; \\
\hline & & & $40-50 \mathrm{~km}^{*}$ from $50+\mathrm{km}$ \\
\hline \multirow[t]{5}{*}{ E. histolytica from MK } & 30.841 & $<2.2 \mathrm{e}^{-16}$ & 0-10 km* from $20-30 \mathrm{~km}, 40-50 \mathrm{~km}$; \\
\hline & & & $10-20 \mathrm{~km} *$ from $20-30 \mathrm{~km}, 40-50 \mathrm{~km}$; \\
\hline & & & $20-30 \mathrm{~km} *$ from $30-40 \mathrm{~km}, 50+\mathrm{km}$; \\
\hline & & & $30-40 \mathrm{~km}^{*}$ from $40-50 \mathrm{~km}$; \\
\hline & & & $40-50 \mathrm{~km} *$ from $50+\mathrm{km}$ \\
\hline
\end{tabular}

Asterisks denote significant differences between distance categories.

incorporated human behavior and both the density and movement of the disease vector - the tsetse fly (Glossina spp.) [10]. Thus, ABMs can be informative for disease management by enabling researchers to model the behavioral patterns of hosts, reservoirs, and vectors, across increasingly complex landscapes.

\section{Conclusion}

In summary, GIS-enabled agent-based models, such as LiNK, are capable of including important information regarding landscape heterogeneity and host behavior and are thus able to make accurate predictions about host dispersal and pathogen transmission patterns in complex landscapes. The significance of incorporating both host movement and landscape information into predictive models has previously been unrecognized. For example, without the inclusion of this data into our model and analyses, how the landscape and host movement together favor a less virulent pathogen within macaque populations, while concurrently allowing for the occasional, yet significant transmission of the more virulent pathogen in dispersing macaques would not have emerged as a relevant, and significant, finding. Utilizing these layers of additional data in modeling has the potential to target disease management efforts, identify areas of cryptic transmission events, and foresee potential unintended ecological consequences of disease management strategy implementation, especially in complex, anthropogenic landscapes. While our analysis focused on directly transmitted parasites, ABMs have been 
successfully implemented for parasites with more complex, indirect life cycles. Thus, GIS-enabled ABMs have the potential to inform management decisions and policies developed in response to both disease outbreaks and chronic, invasive pathogens in wildlife populations.

\section{Additional files}

Additional file 1: ODD Protocol [28, 30, 31, 33, 44, 52, 68].

Additional file 2: Biological Relevance Verification \& Validation Results.

\section{Abbreviations}

LiNK: Named for the authors of the model Lane, Neiderweiser, and Kennedy, this is the agent-based model developed to understand spatial and temporal pathogen transmission patterns; GIS: Geographic Information Systems; ABM: Agent-based Model; ODD: Overview Design concepts, and Details.

\section{Competing interests}

The authors declare that they have no competing interests.

\section{Authors' contributions}

KELD was involved in all aspects of this manuscript, including funding, experimental design, model development and data analysis, post processing development, discussion and writing. RCK was involved in experimental design, model development and data analysis, post processing development, discussion and writing. SMNA was involved in experimental design, model development, post processing development and thoughtful discussion. GRM was involved in experimental design, model development, and thoughtful discussion. $\mathrm{HH}$ was involved in funding, experimental design, model development and data analysis, discussion and writing. AF was involved in funding, experimental design, model development and data analysis, discussion and writing. All authors read and approved the final manuscript.

\section{Acknowledgements}

The authors would like to thank Udayana Universitas, Pusat Kajian Primata. We would also like to thank Gerhard Neiderweiser, Adeline Dozois, and Amy Klegarth for their helpful comments and insights. This research was supported in part by the Notre Dame Center for Research Computing, with valuable assistance provided by Paul Brenner. This work was supported by funding from the National Science Foundation (BSC-0629787), the Leakey Foundation, and the University of Notre Dame. All collections were approved by the University of Notre Dame IACUC (protocol 07-001 and 09-011) and the Indonesian Institute of Science (permit number 662.02/1090.DIII).

\section{Author details}

'Department of Biological Sciences, University of Notre Dame, Notre Dame, IN, USA. ${ }^{2}$ Department of Computer Science \& Engineering, University of Notre Dame, Notre Dame, IN, USA. ${ }^{3}$ Department of Anthropology, University of Notre Dame, Notre Dame, IN, USA. ${ }^{4}$ Department of Bioengineering and Therapeutic Services, University of California, San Francisco, USA. ${ }^{5}$ Current address: Odum School of Ecology, University of Georgia, Athens, GA, USA.

Received: 20 February 2013 Accepted: 9 September 2013 Published: 25 September 2013

\section{References}

1. Hess GR, Randolph SE, Arneberg P, Chemini C, Furlanello C, Harwood J, Roberts MG, Swinton J: Spatial aspects of disease dynamics. In The Ecology of Wildlife Diseases. Edited by Hudson PJ, Rizzolo A, Grenfell BT, Heesterbeek H, Dobson AP. Oxford, UK: Oxford University Press; 2001:102-118.

2. Lam SK, Chua KB: Nipah virus encephalitis outbreak in Malaysia. Clin Infect Dis 2002, 34(S2):S48-S51.

3. Riley S: Large-scale spatial-transmission models of infectious disease. Science 2007, 316:1298-1301.

4. Real LA, Biek R: Spatial dynamics and genetics of infectious disease on heterogeneous landscapes. J R Soc Interface 2007, 4:935-948.
5. Crais RF, Ellis JH, Glass GE: Forecasting the geographical spread of smallpox cases by air travel. Epidemiol Infect 2003, 131:849-857.

6. Crowl TA, Crist TO, Parmenter RR, Belovsky G, Lugo AE: The spread of invasive species and infectious disease as drivers of ecosystem change. Front Ecol Environ 2008, 6(5):238-246.

7. Keeling MJ, Woolhouse MEJ, Shaw DJ, Matthews L, Chase-Topping M, Haydon DT, Cornell ST, Kappey J, Wilesmith J, Grenfell BT: Dynamics of the 2001 UK foot and mouth epidemic: stochastic dispersal in a heterogeneous landscape. Science 2001, 294:813-817.

8. Atti ML C d, Merler S, Rizzo C, Ajelli M, Massari M, Manfredi P, Furlanello C, Scalia Tombo G, lanelli M: Mitigation measures for pandemic influenza in Italy: An individual based model considering different scenarios. PLoS One 2008, 3(3):1-11.

9. Remais J, Akullian A, Ding L, Seto E: Analytical methods for quantifying environmental connectivity for the control and surveillance of infectious disease spread. J R Soc Interface 2010, 7:1181-1193.

10. Muller G, Grebaut P, Gouteux JP: An agent-based model of sleeping sickness: simulation trials of a forest focus in southern Cameroon. J R Biologies 2004, 327:1-11.

11. Grenfell BT, Dobson AP: Ecology of Infectious Diseases in Natural Populations. Cambridge: Cambridge University Press; 1995.

12. Morens DM, Folkers GK, Fauci AS: The challenge of emerging and re-emerging infectious diseases. Nature 2004, 430:242-249.

13. Jones KE, Patel NG, Levy MA, Storeygard A, Balk D, Gittleman JL: Global trends in emerging infectious diseases. Nature 2008, 451:990-994.

14. Eisenberg JNS, Brookhart MA, Rice G, Brown M, Colford JM Jr: Disease transmission models for public health decision making: Analysis of epidemic and endemic conditions caused by waterborne pathogens. Environ Health Persp 2002, 110(8):783-790.

15. Patz JA, Daszak P, Tabor GM, Aguirre AA, Pearl M, Epstein J, Wolfe ND, Kilpatrick AM, Foufopoulos J, Molyneux D, Bradley DH, Members of the Working Group on Land Use Change Disease Emergence: Unhealthy Landscapes: Policy Recommendations on Land Use Change and Infectious Disease Emergence. Environ Health Persp 2004, 112(10):1092-1098.

16. Koopman JS: Modeling Infection Transmission - the Pursuit of Complexities That Matter. Epidemiology 2002, 13(6):622-624.

17. Koopman JS, Lynch JW: Individual causal models and population system models in epidemiology. Am J Public Health 1999, 89(8):1170-1174.

18. Rogers DJ, Randolph SE: Studying the global distribution of infectious diseases using GIS and RS. Nat Rev Microbiol 2003, 1:231-237.

19. Colwell RR: Global climate change and infectious disease: the cholera paradigm. Science 1996, 274:2025-2031.

20. Eisen RJ, Enscore RE, Biggerstaff BJ, Reynolds PJ, Ettestad P, Brown T, Pape J, Tanda D, Levy CE, Engelthaler DM, Cheek J, Bueno R, Targhetta J, Montenieri JA, Gage KL: Human plague in the southwestern United States, 1957-2004: spatial models of elevated risk of human exposure to Yersinia pestis. J of Med Entomol 2007, 44(3):530-537.

21. Mungrue K, Mahabir R: The rabies epidemic in Trinidada of 1923 to 1937: an evaluation with a geographic information system. Wild Environ Med 2009: . doi:10.1016/j.wem.2010.11.001.

22. Castillo-Riquelme M, Chalabi Z, Lord J, Guhl F, Campbell-Lendrum D, Davies C, Fox-Rushby J: Modelling geographic variation in the cost-effectiveness of control policies for infectious diseases: The example of Chagas disease. J Health Econ 2008, 27:405-426.

23. Eubank S, Guclu H, Anil Kumar VS, Marathe MV, Srinivasan A, Toroczkai Z, Wang N: Modelling disease outbreaks in realistic urban social networks. Nature 2004, 429:180-184.

24. Meyers LA: Contact network epidemiology: bond percolation applied to infectious disease prediction and control. B Am Math Soc 2007, 44(1):63-86.

25. Grimm V, Railsback SF: Individual-based modeling and ecology. Princeton, NJ: Princeton University Press; 2005

26. Segovia-Juarez JL, Gangul S, Krischner D: Identifying control mechanisms of granuloma formation during M. tuberculosis infection using an agentbased model. J Theor Biol 2004, 231:357-376.

27. Thierry B: The Macaques: a double-layered social organization. In Primates in Perspective. Edited by Campbell CJ, Fuentes A, MacKinnon KC, Panger M, Bearder SK. Oxford, UK: Oxford University Press; 2007:224-239.

28. Evans BJ, Supriatna J, Andayani N, Melnick DJ: Diversification of Sulawesi macaque monkeys: Decoupled evolution of mitochondrial and autosomal DNA. Evolution 2003, 57:1931-1946. 
29. Lane KE, Lute M, Arta Putra IGA, Wandia IN, Hollocher H, Fuentes A: Pests, pestilence, and people: the long-tailed macaque and its role in the cultural complexities of Bali. In Indonesian Primates. Edited by Gursky S, Supriatna J. New York, NY: Springer; 2010:239-248.

30. Wheatley BP: The sacred monkeys of Bali. Prospect Heights, IL: Wavelend Press, Inc; 1999.

31. Fuentes A, Southern M, Suaryana KG: Monkey forests and human landscapes: is extensive sympatry sustainable for Homo sapiens and Macaca fascicularis in Bali? In Commensalism and Conflict: The primatehuman interface. Edited by Patterson J. American Society of Primatology Publications; 2005.

32. Southern MW: An assessment of potential habitat corridors and landscape ecology for long-tailed macaques (Macaca fascicularis) on Bali, Indonesia, Master's thesis. WA: Central Washington University; 2002.

33. Jasmer DP, Goverse A, Smant G: Parasitic nematode interactions with mammals and plants. Annu Rev Phytopathol 2003, 41:245-270.

34. Roberts LS, Janovy J: Foundations of Parasitology, 8th ed. New York, NY: McGraw-Hill; 2009.

35. Lane KE, Holley C, Hollocher H, Fuentes A: The anthropogenic environment lessens the intensity and prevalence of gastrointestinal parasites in Balinese long-tailed macaques (Macaca fascicularis). Primates 2011, 52(2):117-128.

36. Danson FM, Craig PS, Man W, Shi D, Giraudoux P: Landscape dynamics and risk modeling of human alveolar echinococcis. Photo Eng Rem Sens 2004, 70(3):359-366.

37. Giraudoux P, Craig PS, Delattre P, Boa G, Bartholomot B, Harraga S, Quere J-P, Raoul F, Wang Y, Shi D, Vuitton D-A: Interactions between landscape changes and host communities can regulate Echinococcus multilocularis transmission. Parasit 2003, 127:S121-S131.

38. Trejos-Macia G, Estrada A, Cabrera AGM: Survey of helminth parasites in populations of Alouatta palliate Mexicana and A. pigra in continuous and in fragmented habitat in southern Mexico. Int J Primat 2007, 28:931-945.

39. Ryan SJ, Brashares JS, Walsh C, Milbers K, Kilroy C, Chapman CA: A survey of gastrointestinal parasite of olive baboobs (Papio Anubis) in human settlement areas of Mole National Park, Ghana. J Parasit 2012, 98(4):885-888.

40. Rivera WL, Yason ADL, Adao DEV: Entamoeba histolytica and E. dispar infections in captive macaques (Macaca fascicularis) in the Philippines. Primates 2010, 51(1):69-74.

41. Tachibana H, Yanagi T, Akatsuka A, Kobayash S, Janbara H, Tsutsumi V: Isolation and characterization of a potentially virulent species of Entamoeba nuttali from captive Japanese macaques. Parasit 2009 136(10):1169-1177.

42. Feng M, Yang B, Yang L, Fu YF, Zhuang YJ, Liang LG, Xu G, Cheng XJ, Tachibana $\mathrm{H}$ : High prevalence of Entamoeba infections in captive long-tailed macaques in China. Parasit Res 2011, 109(4):1093-1097.

43. Grimm V, Berger U, DeAngelis DL, Polhill JG, Giske J, Railsback SF: The ODD protocol: a review and first update. Ecol Model 2010, 221:2760-2768.

44. Java: http://java.sun.com.

45. Repast: http://sourceforge.repast.net.

46. OpenMap: http://openmap.bbn.com.

47. GeoTools: http://geotools.codehaus.org.

48. JTS Topology Suite: http://www.vividsolutions.com/jts/jtshome.htm.

49. Grimm V, Berger U, Bastiansen F, Eliassen S, Ginot V, Giske J, Goss-custard J, Grand T, Heinz SK, Huse G, Huth A, Jepsen JU, Jorgensen C, Mooij WM, Muller B, Pe'er G, Piou C, Railsback SF, Robbins AM, Robbins MM, Rossmanith E, Ruger N, Strand E, Souissi S, Stillman RA, Vabo R, Visser U, DeAngelis DL: A standard protocol for describing individual-based and agent-based models. Ecol Model 2006, 198:115-126.

50. Kennedy RC, Lane KE, Fuentes A, Hollocher H, Madey G: A GIS aware agent-based model of pathogen transmission. Int J Intell Contr Syst 2009, 14(1):51-61.

51. Leduc A, Drapeau P, Bergeron Y, Legendre P: Study of spatial components of forest covers using partial Mantel tests and path analysis. J Veg Science 1992, 3(1):69-78.

52. Zar JH: Biostatistical Analysis. Upper Saddle River, NJ: Prentice Hall; 1999.

53. Wright S: Isolation by distance. Genetics 1943, 28:114-138.

54. Rousset F: Genetic differentiation and estimation of gene flow from F-statistics under isolation by distance. Genetics 1997, 145:1219-1228.

55. Slatkin M: Isolation by distance in equilibrium and non-equilibrium populations. Evolution 1993, 47(1):264-279.
56. Stanley SL: Pathophysiology of ameobiasis. Trends Parasito/ 2001, 17(6):280-285.

57. De Garine-Waichatitsky M, Caron A, Kock R, Tschopp R, Munyeme M, Hofmeyr M, Michel A: A review of bovine tuberculosis at the wildlifelivestock-human interface in sub-Saharan Africa. Epidem and Infect 2012, 141(7):1342-1356.

58. Amouroux E, Desvaux S, Drogoul A: Towards Virual Epidemiology: an agent-based approach to the modeling of H5NB1 propogation and persistence in North Vietnam. In Intelligent agents and multi-agent systems. Berlin, Germany: Springer Berlin; 2008.

59. Laurenson MK, Mlengeya T, Shiferaw F, Cleaveland S: Approaches to disease control in domestic canids for the conservation of wild carnivores. Cambridge, UK: IUCN Publications; 2004.

60. Boadella M, Vicente J, Ruiz-Fons F, de la Fuente J, Gortazar C: Effects of culling Eurasian wild boar on the prevalence of Mycobacterium bovis and Aujeszky's disease virus. Prevent Vet Med 2011, 107(3-4):214-221.

61. Beeton N, McCallum H: Models predict that culling is not a feasible strategy to prevent extinction of Tasmanian devils from facial tumour disease. J Appl ECO, 48(6):1315-1323.

62. Donnelly CA, Woodroffe R, Cox DR, Bourne FJ, Cheeseman CL, CliftonHadley RS, Wei G, Gettinby G, Gilks P, Jenkins H, Johnston WT, LeFevre AM, Mclnerney JP, Morrison WI: Positive and negative effects of widespread culling on tuberculosis on cattle. Nature 2006, 439(16):843-846.

63. Woodroffe R, Donnelly CA, Cox DR, Bourne FJ, Cheeseman CL, Delahay RJ, Gettinby G, Mclnerney JP, Morrison Wl: Effects of culling on badger Meles meles spatial organization: implications for the control of bovine tuberculosis. J Appl Ecol 2006, 43(1):1-10.

64. Woodroffe R, Donnelly CA, Wei G, Cox DR, Bourne FJ, Burke T, Butlin RK, Cheeseman CL, Gettinby G, Gilks P, Heges S, Jenkins HE, Johnston WT, Mclnerney JP, Morrison WI, Pope LC: Social group size affects Mycobacterium bovis infection in European badgers (Meles meles). J Anim Ecol 2009, 78:818-827.

65. Woodroffe R, Donnelly CA, Cox DR, Gilks P, Jenkins HE, Johnston WT, LeFevre AM, Bourne FJ, Cheeseman CL, Clifton-Hadley RS, Gettinby G, Hewinson RG, Mclnerney JP, Mitchell AP, Morrison WI, Watkins GH: Bovine tuberculosis in cattle and badgers in localized culling areas. J Wildlife Dis 2009, 45(1):128-143.

66. Levin R: Preparing for Uncertainty. Ecosyst Health 1995, 1:47-57.

67. Bonnell TR, Sengupta RR, Chapman CA, Goldberg TL: An agent-based model of red colobus resources and disease dynamics implicates key resource sites as hot spots of disease transmission. Ecol Model 2010, 221(20):2491-2500.

68. Arifin SMN, Kennedy RC, Lane KE, Fuentes A, Hollocher H, Madey G: P-SAM: A PostSimulation Analysis Module for Agent-Based Models. Ottawa, ON: Paper presented at Proceedings of the Summer Computer Simulation Conference; 2010.

doi:10.1186/1472-6785-13-35

Cite this article as: Lane-deGraaf et al:: A test of agent-based models as a tool for predicting patterns of pathogen transmission in complex landscapes. BMC Ecology 2013 13:35.

\section{Submit your next manuscript to BioMed Central and take full advantage of:}

- Convenient online submission

- Thorough peer review

- No space constraints or color figure charges

- Immediate publication on acceptance

- Inclusion in PubMed, CAS, Scopus and Google Scholar

- Research which is freely available for redistribution 